\title{
Development of engineering calculator for heating systems
}

\author{
Andrei Melekhin* \\ Moscow State University of Civil Engineering, Yaroslavskoe shosse, 26, Moscow, 129337, Russia
}

\begin{abstract}
The author has developed an engineering calculator for calculating the heat flow for heating buildings according to the enlarged parameters of the object. The algorithm of the calculator is based on the method of determining the amount of heat energy and heat carrier in water systems of municipal heat supply. The author carried out a systematic analysis of thermal loads on heating of buildings in Russia according to the data of implemented building projects. With this in mind, new coefficients $\mathrm{a}, \mathrm{n}$ were calculated to determine the specific heating characteristics of the building for newly constructed buildings. The algorithm for calculating the heating of buildings according to the enlarged parameters of the object is corrected. The calculation algorithm is implemented in the software
\end{abstract}

\section{Introduction}

The relevance of the topic is due to the development of digital technologies for solving engineering problems, including the construction field. Currently, many regulatory documents have been developed codes of rules.

This documentation is constantly updated over time. The problem is the lack of adaptation of this regulatory documentation for the layman. Taking into account the development of public and other procurement of services and materials, their purchase is required. These procedures involve specialists who do not have knowledge in the construction field. In addition, often in low-rise construction, not qualified specialists or ordinary people are involved in the purchase of building materials or the selection of equipment. To solve this problem of selecting building materials, calculating the heat load, selecting construction equipment and feasibility study of the calculation, an engineering calculator can be used. This engineering calculator is implemented in a software package with the introduction of technical and economic calculation algorithms based on regulatory documentation. The uniqueness of the technical and economic algorithms developed by the author is to find the optimal parameters of the ratio of economic and technical parameters by solving problems of multi-criteria optimization of parameters.

The calculation algorithm is based on the method of determining the amount of heat energy and heat carrier in water systems of municipal heat supply $[1,3,4,5,6]$. The disadvantage of this method is overestimated specific heating characteristics, as a result of which, when calculating thermal loads according to the set of rules by designers [2], the

\footnotetext{
* Corresponding author: melehin2006@yandex.ru
} 
data with the method for enlarged parameters of the object significantly differed [1]. This is justified by the introduction of new building materials for thermal protection of buildings, the use of automated individual heat points, new heating devices with higher heat transfer coefficients, the use of new materials for thermal protection of pipelines, as a result of which the consumption of thermal energy for heating buildings and reducing the specific heating characteristics of buildings are reduced [9-14] .

\section{Methods}

To solve this problem, a systematic analysis of thermal loads on heating of buildings built after 2000 years in Russia was carried out according to the data of implemented projects in various climatic zones. As a result, the coefficients a, $n$ were corrected for calculating the specific heat flux in formula 4 . The new coefficients a, $\mathrm{n}$ are obtained empirically, including for various purposes of buildings (residential and other purposes).

The algorithm for calculating the heat flow to the building implemented in the engineering calculator is described below.

The heat flow for building heating (hourly) is determined by the following formula [1]:

$$
Q_{\mathrm{o}}=\alpha \cdot V \cdot q_{\mathrm{o}}\left(t_{\mathrm{in}}-t_{\text {out }}\right) \cdot\left(1+K_{i}\right)
$$

where $\alpha$ is the correction factor (taken in accordance with Table 1 [1]); V is construction heated volume, $\mathrm{m}^{3} ; \mathrm{q}_{\mathrm{o}}$ is specific heat flux for heating of the building Watt $/ \mathrm{M}^{3} \cdot \mathrm{grad} ; t_{\mathrm{in}}$ is the air temperature in the heated room in accordance with [7], grad.; $\mathrm{t}_{\mathrm{out}}$ is outdoor air temperature for heating design in accordance with [8], grad.; $\mathrm{K}_{\mathrm{i}}$ is coefficient of air infiltration for heating buildings.

Specific heat flow for building determined by the formula:

$$
q_{\mathrm{o}}=\frac{a}{\sqrt[n]{V}}
$$

where $a, n$ are the new coefficients obtained (for residential buildings $a=1, n=7$; for other buildings $a=1, n=5$ ), $\mathrm{V}$ is the heated building volume, $\mathrm{m}^{3}$.

The coefficient of air infiltration for heating buildings is determined by the formula:

$$
K_{i}=0,01 \cdot \sqrt{2 \cdot g \cdot L \cdot\left(1-\frac{273+t_{\text {out }}}{273+t_{\text {in }}}\right)+\omega^{2}}
$$

where $g$ is the acceleration of gravity, $\mathrm{m} / \mathrm{s}^{2} ; L$ is the height of the building, $\mathrm{m} ; \omega$ is the average wind speed during the heating period according to [8], $\mathrm{m} / \mathrm{s}$.

To create an engineering calculator, the thermophysical characteristics are translated into mathematical ones $\left(\mathrm{R}_{1}, \mathrm{R}_{2}, \mathrm{R}_{5}, \mathrm{~B}, \mathrm{O}, \mathrm{P}, \mathrm{F}, \mathrm{L}, \mathrm{N}, \mathrm{M}, \mathrm{I}, \mathrm{J}\right)$. DHTML programming can be used as an implementation of the calculation algorithm [15-20]. Formulas 1-3 provide an algorithm for calculating the heat flow of energy for heating residential and other buildings. This calculation algorithm can be used in the development of computer programs. To calculate the heat flow to the building, enter the initial data.

\section{Results}

The author developed algorithms feasibility study for engineering systems, according to the rulebook for thermal protection of buildings [2] and enlarged the definition of the heat flux on the integrated parameters of the object [1]. 
The algorithm for calculating the heat flow for heating buildings based on the enlarged parameters of the object is based on the method for determining the amount of heat energy and heat carrier in water systems of municipal heat supply [1] . A systematic analysis of the thermal loads on the heating of buildings in Russia is carried out according to the data of the implemented building projects. With this in mind,new coefficients a, $\mathrm{n}$ are calculated to determine the specific heating characteristics of the building for newly constructed buildings. The calculation algorithm is implemented in the software product, using html programming.

Figure 1 shows a comparison of the specific heat flow for heating residential buildings before 1958, from 1958 to 2000, and from 2000 of construction. The specific heat flow for heating buildings in temporary intervals ranges up to $30 \%$. Moreover, the value of the specific heat flux for buildings after 2000 and for buildings before 1958 is less by $15 \%$, and for buildings before 1958 and from 1958 to 2000 is less by $15 \%$. The difference in the specific values of the heat flow for heating over time intervals is explained by the introduction of the global construction of a complex of residential buildings in the country according to standard projects at each time.

Until 1958, the construction of residential buildings was carried out from bricks, cinder blocks (with the exception of wooden houses, including those finished with cement plaster) with an increased wall thickness, which made it possible to provide a good required heat transfer resistance of building enclosing structures.

In the 1950 to provide prefabricated housing for the population, introduced the socalled construction of buildings low coefficients of thermal resistance of walls, respectively, to compensate for comfortable temperatures in residential areas - increased consumption of heat flow on heating.

After 2000, the construction of buildings made of multi-layer enclosing structures made of new building materials with reduced heat transfer resistance coefficients (ventilated facades, etc.), the introduction of double-glazed windows, individual heat points, automation of heating systems, which allowed to reduce the specific heat flow for heating.

Figure 2 shows a graph of the dependence of the specific heat flow for heating buildings before 1958, from 1958 to 2000 , and after 2000. The data are given according to the methodology for determining the amount of heat energy and heat carrier in water systems of municipal heat supply [1], with the exception of the schedule for buildings after 2000. For the graph after 2000,the coefficients a, $\mathrm{n}$ are derived, taking into account empirical data from building projects.

Currently, this method is not used everywhere in the Russian Federation, although in some heat supply organizations it was used and is used for concluding contracts with consumers and calculating for heat energy in the absence of heat meters or during their nonworking condition, the absence of design documentation for the heating and ventilation section. The use of these values is possible in different time intervals, depending on the materials of the enclosing structures. This should be taken into account when choosing specific values of the heat flow for heating buildings. 


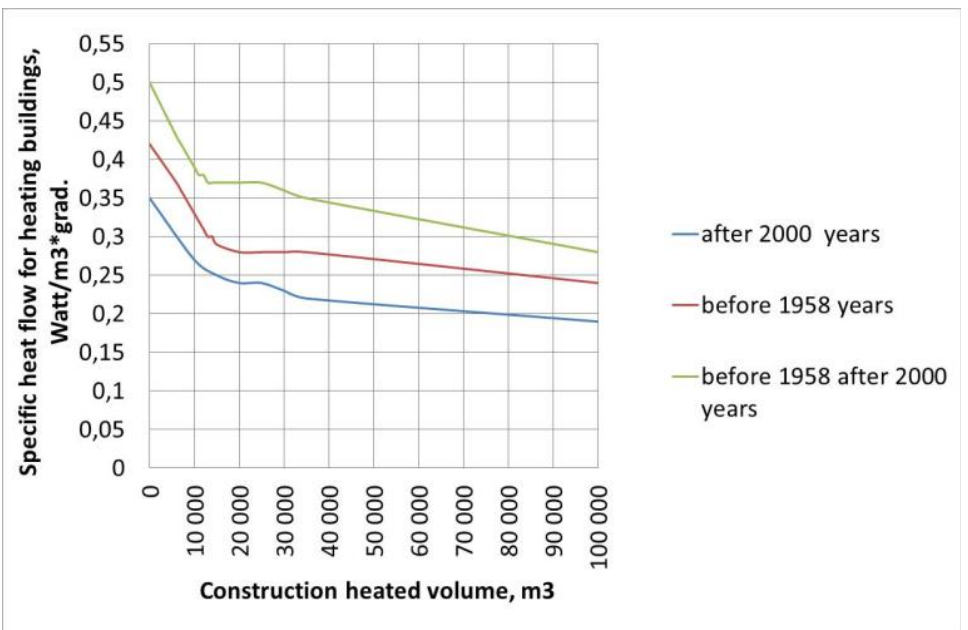

Fig. 1. Diagram of the dependence of the specific heat flow for heating buildings according to data and new data of coefficients $a, n$.

The analysis of the specific heat consumption for heating buildings according to the current regulatory documentation is carried out. According to table No. 14 of section No. 10 [2], the specific heat flow for heating buildings for various purposes is determined by the number of storeys of buildings or according to table No. 13 [2] by the area of buildings.

The figure 2 shows a diagram of the dependence of the specific heat flow for heating a building on the number of floors of a building for various purposes according to Table No. $14[2]$.

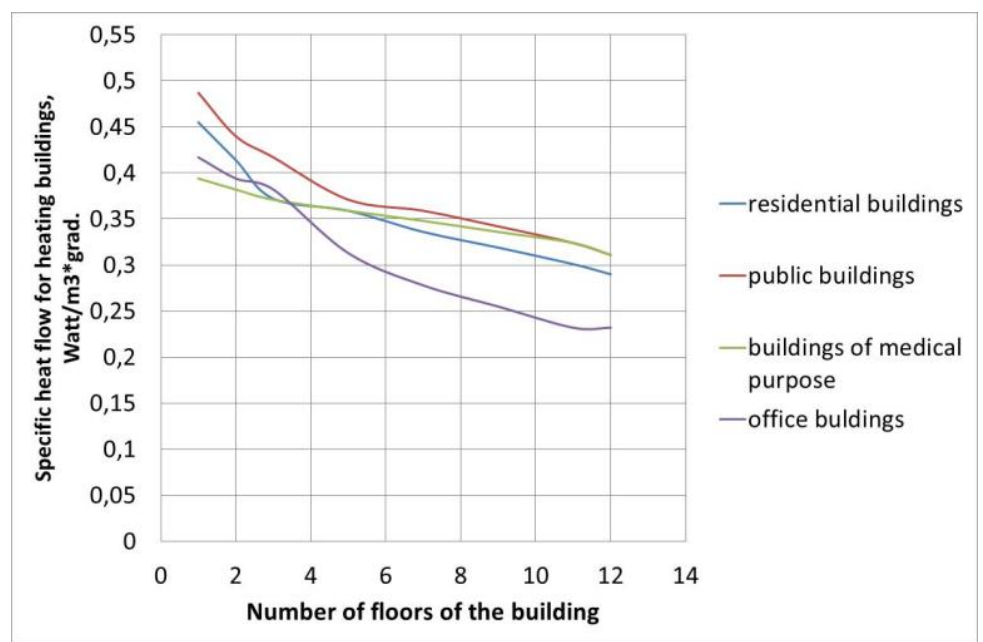

Fig. 2. Diagram of the dependence of the specific heat flow on the heating of buildings according to the data [2].

The table №1 shows the data for the calculation in the engineering calculator of residential and public building projects in the Russian Federation. The heated volume of buildings varies from 546 to $230 \mathrm{~m}^{3}$. The outdoor air temperature for designing a heating system varies from -15 to -41 degrees. The wind speed varies from 2 to $4.5 \mathrm{~m} / \mathrm{s}$. The height of the building varies from 6 to $43 \mathrm{~m}$. The indoor air temperature in buildings varies from 12 to 20 degrees. The coefficient $a$ for outdoor air temperature varies from 0.89 to 1.15 . The coefficient $n$ varies from 5 to 7 . 
Table 1. Accepted parameters for building calculations in the engineering calculator

\begin{tabular}{|c|c|c|c|c|c|c|c|c|}
\hline № & name of the building project & $\begin{array}{c}\text { construc } \\
\text { tion } \\
\text { heated } \\
\text { volume, } \\
\mathrm{m}^{3}\end{array}$ & $\begin{array}{c}\text { speed } \\
\text { wind, } \\
\mathrm{m} / \mathrm{s}\end{array}$ & $a$ & $n$ & $\begin{array}{c}\text { building } \\
\text { height, } \\
\text { m }\end{array}$ & $\begin{array}{l}\text { indoor } \\
\text { tempe } \\
\text { rature, } \\
\text { grad. }\end{array}$ & $\begin{array}{l}\text { outdoor } \\
\text { air } \\
\text { tempera } \\
\text { ture, } \\
\text { grad. }\end{array}$ \\
\hline 1 & $\begin{array}{l}\text { 3-storey } 36 \text { apartment } \\
\text { residential building in the } \\
\text { Astrakhan region }\end{array}$ & 8593 & 3,8 & 1,15 & 7 & 13 & 20 & -21 \\
\hline 2 & $\begin{array}{l}\text { Low-rise 12-apartment } \\
\text { building in the Novosibirsk } \\
\text { region }\end{array}$ & 2899 & 3,6 & 1,08 & 7 & 9 & 20 & -25 \\
\hline 3 & $\begin{array}{l}72 \text { apartment residential } \\
\text { building in Simferopol }\end{array}$ & 16867 & 4,5 & 1,29 & 7 & 31 & 20 & -15 \\
\hline 4 & $\begin{array}{l}\text { Individual 2-storey residential } \\
\text { building in the city of Saratov }\end{array}$ & 546 & 3,3 & 1,08 & 7 & 9 & 20 & -25 \\
\hline 5 & $\begin{array}{l}\text { Administrative building in the } \\
\text { Chelyabinsk region }\end{array}$ & 2263 & 2,3 & 0,98 & 7 & 12 & 20 & -32 \\
\hline 6 & $\begin{array}{l}\text { Center for Cultural } \\
\text { Development in the } \\
\text { Krasnoyarsk region }\end{array}$ & 12825 & 2,5 & 0,89 & 5 & 14,5 & 18 & -41 \\
\hline 7 & $\begin{array}{l}\text { 12-storey residential building } \\
\text { in Moscow }\end{array}$ & 48545 & 2 & 1,08 & 7 & 43 & 20 & -25 \\
\hline 8 & $\begin{array}{l}\text { Production building in the Ural } \\
\text { region }\end{array}$ & 2654 & 3 & 0,95 & 5 & 6 & 12 & -35 \\
\hline 9 & $\begin{array}{l}\text { Kindergarten for } 280 \text { children } \\
\text { in the Ulyanovsk region }\end{array}$ & 23030 & 4,4 & 0,97 & 5 & 8,2 & 20 & -33 \\
\hline
\end{tabular}

Figure 3 shows the trends in the cost of heating buildings for the project and the engineering calculator. The project's heat consumption ranges from 24 to $615 \mathrm{~kW}$ att. The heat consumption when calculated in the engineering calculator is from 25.8 to 563.4 $\mathrm{kWatt}$. The difference between the project data and the calculation in the engineering calculator is from 6.2 to $30.1 \%$. Perhaps the difference in the calculations for the project and in the engineering calculator may be due to the incorrect calculation of heat losses from the enclosing structures of buildings. The calculation of the heat flow in the engineering calculator can be used for preliminary assessment and selection of heating.

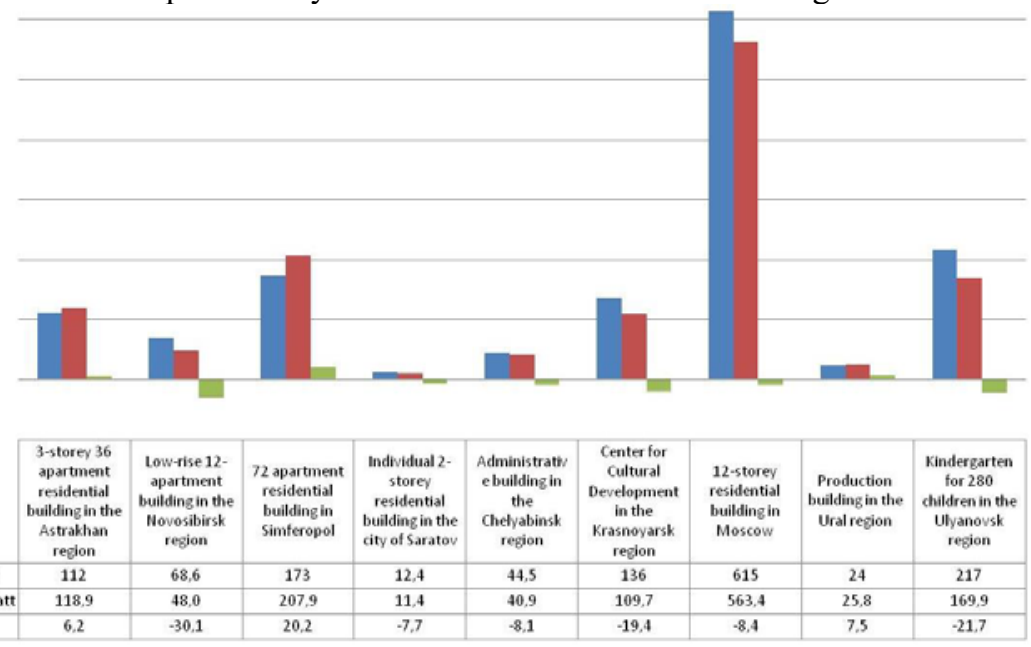

Fig. 3. Trends of the heat flow for heating buildings 


\section{Conclusion}

The relevance of the topic is due to the development of digital technologies for solving engineering problems, including in the construction field. Currently, many regulatory documents have been developed. This documentation is constantly updated over time. The problem is the lack of adaptation of this regulatory documentation for the layman. To solve this problem of calculating the heat load on a building, an engineering calculator can be used. The calculation algorithm of the engineering calculator is based on the method of determining the amount of heat energy and heat carrier in water systems of municipal heat supply. The disadvantage of this method is an overestimated specific heating characteristic for heating buildings. Therefore, when calculating thermal loads according to the regulatory documentation [2], the methodology for the enlarged parameters of the object [1] differed significantly. This is justified by the introduction of new building materials for the thermal protection of buildings, the use of automated individual heat points, new heating devices with higher heat transfer coefficients, the use of new materials for the thermal protection of pipelines. This led to a decrease in the consumption of heat energy for heating buildings and a decrease in the specific heating characteristics of buildings. A systematic analysis of the heat loads on the heating of buildings built after 2000 in Russia is carried out according to the data of the implemented projects in various climatic zones. As a result, the coefficients a, $n$ were adjusted to calculate the specific heat flow. The new coefficients a,n were obtained empirically, including for various purposes of buildings (residential and other purposes). An algorithm for calculating the heat flow per building, implemented in an engineering calculator based on programming in DHTML.

\section{References}

1. MDS 41-4.2000, Method of determining the amount of heat energy and heat carrier in water systems of municipal heat supply, Russia, (2000).

2. SP 50.13330.2012, Thermal protection of buildings, Russia, (2012).

3. A.A.Melekhin, Workshop on the calculation of heat flows for the heat supply of buildings according to the enlarged parameters of the object, ISBN 978-5-9973-54992, Sputnik-plus, Moscow, Russia (2020).

4. A.A.Melekhin, Development of an engineering calculator for calculating the heat flow for heating buildings, Natural and technical sciences, № 1(151), pp. 161-163, Russia, (2021).

5. A.A.Melekhin, Engineering systems of reconstruction and restoration facilities, MGSU, Moscow, Russia (2020).

6. M.V. Bodrov, V.U. Kuzin, M.S. Morozov, A.A. Smykov, Determination of the economic advantage of using radiant heating systems based on water infrared emitters, Collection of reports of the VIII Russian Scientific and Technical Conference dedicated to the Centenary of MISI-MGS, Russia, (2020).

7. GOST 30494-2011, Residential and public buildings. The parameters of the microclimate in the premises, Russia, (2011).

8. SP 131.13330.2012, Construction climatology, Russia, (2012).

9. Ivan Oropeza-Perez, Development of a cooling-load calculator for the Mexican conditions of climate, construction and occupancy, Procedia Engineering Volume 205, 2017, Pages 1115-1122, Chine (2017) 
10. Samantha Mudiea, Maria Vadhatib, Low energy catering strategy: insights from a novel carbon-energy calculator, Energy Procedia, Volume 123, September 2017, Pages 212219, UK (2017).

11. Ugis Sarma, Gatis Bazbauers, Algorithm for calculation of district heating tariff benchmark, Energy Procedia, Volume 128, September 2017, Pages 445-452, Latvia, (2017).

12. Jin Woo Moon, Young Kwon Yang, Eun Ji Choi, Young Jae Choi, Kwang-Ho Lee, Yong-Shik Kim, Bo Rang Park, Development of a control algorithm aiming at costeffective operation of a VRF heating system, Applied Thermal Engineering, Volume 149, 25 February 2019, Pages 1522-1531 (2019).

13. Allan R.StarkeaJosé, M.Cardemilb, Sergio Collea, Multi-objective optimization of a solar-assisted heat pump for swimming pool heating using genetic algorithm, Applied Thermal Engineering, Volume 142, September 2018, Pages 118-126, (2018).

14. A.A. Dekterev, K.Yu. Litvintsev, A.A. Gavrilov, E.B. Kharlamov, S.A. Filimonov, The development of free engineering software package for numerical simulation of hydrodynamics, heat transfer, and chemical reaction processes, bulletin of the South Ural State University, vol. 10, is. 4, pp 105-112, Russia, (2017).

15. G. G. Kashevarova, A. S. Martirosyan, Software implementation of the algorithm the statistical straggling of the mechanical properties of materials in the design of structures, Advanced Materials Research, vol.684, pp.106-110, Trans Tech Publication, Switzerland, (2013).

16. G.G. Kashevarova, T.B. Permyakova, Numerical methods for solving problems of construction of the computer, Russia, (2007).

17. S.I. Solodushkin, I.F.Iumanova, Web u DHTML, Russia (2018).

18. Frein B, HTML5 and CSS3: Website development for any browsers and devices, ISBN 978-5-496-00185-4, Russia, (2014).

19. E. Meyer, E. Weil., The Definitive Guide,. Sebastopol : O'Reilly Media, ISBN-13 9781449393199, USA, (2017).

20. Web technologies for developers: CSS (eng. Web technology for developers: CSS) [Electronic resource]. URL: https://developer.mozilla.org/ en-US/docs/Web/CSS (accessed 27.09.2018). 